\title{
Changes in nursing students' health one year after starting the nursing degree program
}

\begin{abstract}
Objectives: Aim 1- to describe the health status of nursing students one year after starting the nursing degree program; and Aim 2- to analyze the impact of Stress, Depressive Symptoms, Sleep Quality and Resilience on nursing students' quality of life one year after starting the a nursing degree program.

Method: a longitudinal quantitative research will be done to satisfy the first aim and a methodological study to test the theoretical model proposed (Aim 2). First, all instruments will be calibrated through exploratory and confirmatory factor analysis. Data collection will be performed at two time points through validated instruments in two public Brazilian University from Sao Paulo (state), as follows: first week of classes and one year after the first data collection. ANOVA for repeated measures will be used to compare means of each construct across time. In order to understand the relationships among variables we will use Structural Equations Modeling. Data from both time points will be used to analyze the variation in quality of life and those from the first time point will be used in the analysis of the other constructs. The impact of each construct on the quality of life changes will be described. $P$ values $<0.05$ will be considered statistically significant. Instrument reliability will be determined by Cronbach's Alpha.
\end{abstract}

Expected Results: We intend to better understand those factors that contribute to future nurses' health. Long term this may impact work performance, work satisfaction, and patient care.

Keywords: nursing, nursing students, mental health, factor analysis, statistical
Volume 9 Issue 2 - 2018

\author{
Rodrigo Marques da Silva,' Margaret M \\ Heitkemper, ${ }^{2}$ Cristilene Akiko Kimura, ${ }^{3}$ lel \\ Marciano de Moraes Filho, ${ }^{4}$ Victor Cauê \\ Lopes, ${ }^{5}$ Ana Lúcia Siqueira Costa ${ }^{6}$ \\ 'Nursing Prfessor, Faculty of Sciences and Education Sena Aires, \\ Valparaíso de Goiás (GO), Brazil \\ 2Professor, Department of Biobehavioral Nursing and Health \\ Systems, University of Washington, USA \\ ${ }^{3}$ Institutional attorney, Faculty of Sciences and Education Sena \\ Aires, Brazil \\ ${ }^{4}$ Nursing Professor at Goiytacazes Union Faculty, Brazil \\ ${ }^{5}$ Nursing Professor at High Degree Juinensis Association(AJES), \\ Brazil
}

Correspondence: Rodrigo Marques da Silva, RN, PhD, Nursing Prfessor, Faculty of Sciences and Education Sena Aires, Valparaíso de Goiás (GO), Brazil, Email marques-sm@hotmail.com

Received: November 24, 2017 | Published: March 29, 2018

\section{Background}

Starting the nursing degree program is to an important step towards preparation as a nurse. During this period, students experience the challenges of the clinical setting and are exposed to the demands and obstacles faced by the health care professionals. In addition, nursing students must satisfy curricular requirements and manage their time to attend to social and familial demands. For many these requirements and demands are viewed as stressors.

For Brazilian students, stressors range from in-program expectations such as academic exams and homework to the changes in the levels of requirements between high school and college. ${ }^{2}$ Data from other nursing student populations reveal additional information about academic stressors. These include the first 12 months college activities; the traumatic experiences with a patient's death; the responsibility of taking care of other people; the requirements about academic performance; the interpersonal relationships; their insecurity in doing clinical procedures required in clinical setting during practical classes and curricular internships; and the adaption to those academic requirements. This is in addition to other issues faced by many Brazilians including heavy traffic; time to spent at university; insufficient public transportation, and financial difficulties. ${ }^{3-5}$

To succeed in an academic nursing program, students need to effectively manage their time and engage in behaviors that allow them to make effective use of time. ${ }^{6}$ However, researchers have found that university students usually do not effectively manage their time to satisfy all academic, social and personal demands $0 .{ }^{6,7}$ For nursing students at Rio Grande do Sul (Brazil) time management was perceived as the most stressful aspect of nursing school. ${ }^{8}$
Stressors from academic environment may cause changes in health status of nursing students, including stress, depressive symptoms, poor sleep quality and reduced quality of life. Several researches have been identified situations that work as predictors of nursing student's stress, such as: number of activities and academic training-related tasks; lack of knowledge and professional skills; quality of the relationships with faculty members and nursing team; and the clinical setting. ${ }^{8,9}$ Additionally, ineffective time management may impact on the students' health. Investigation studied 177 first year college students ${ }^{7}$ and found that students who ineffectively manage their time are more likely to experience high stress levels and poor sleep quality. ${ }^{7}$ A study conducted with 174 Australian non nursing students found that time management was significantly and negatively correlated to the levels of perceived stress. ${ }^{10}$

Stress is defined as any stimulus from external or internal environment that taxes or exceeds the adaptation resources of an individual or social system. ${ }^{11}$ It is established that nursing students experience stress. ${ }^{2,4,12,13}$ Among 130 nursing students from South Brazil, 9\% reported high stress and $68 \%$ reported moderate stress on an instrument for the assessment of stress in nursing students. ${ }^{13}$ From a sample of 129 nursing students living in São Paulo, 25\% second and third year students reported high stress. ${ }^{12}$ Stress is significantly correlated to Depressive symptoms, ${ }^{14-17}$ sleep quality ${ }^{18}$ and quality of life. ${ }^{19}$

Depressive symptoms can be defined as a set of emotions and cognitions that may impact on the interpersonal relationships. ${ }^{20}$ In an investigation of 729 USA college students, $16.5 \%$ reported depressive mild symptoms, $30.6 \%$ reported moderate depression, 
and $23.2 \%$ reported severe or moderately severe depression. ${ }^{14}$ Also, a Canadian study found that $34.2 \%$ of university students ${ }^{15}$ were experiencing Depressive Symptoms. In other research performed in China, $6.4 \%$ of high school students reported depressive symptoms. ${ }^{21}$ Depressive symptoms may be associated with other health conditions. Additionally, depressive symptoms may be predictors of poor sleep quality. A study of 3186 Chinese students found that students with depressive symptoms had $2.47(\mathrm{CI}=1.61$ to 3.79$)$ more chance to experience poor sleep quality. ${ }^{21}$

Poor Sleep Quality is defined as tiredness on waking and throughout the day, feeling unrested and non-restored on waking, and the number of awakenings experienced in the night. ${ }^{22}$ Studies found poor sleep quality in $60 \%$ of university students of Chicago ${ }^{18}$ and $71 \%$ of students in California. ${ }^{23}$ Sleep quality may also impact on nursing students' health. When 1074 college students in Texas (USA) were assessed, those with insomnia had lower scores of sleep quality, and higher scores of depression and anxiety. ${ }^{24}$ In other study, after assessing 35 Texan University students through actigraph watch, the findings showed that those with disturbed sleep had higher depression scores. ${ }^{25}$ Additionally, a significant relationship between sleep quality and depressive symptoms $(\mathrm{p}=0.027 ; \mathrm{r}=0.278)^{26}$ was found in students in Sao Paulo (Brazil).

All of these health conditions (stress, sleep quality and depressive symptoms) experienced by nursing students may affect their quality of life. This phenomenon is described as the feeling of well being and it stems from the satisfaction or dissatisfaction in those areas of life considered important for individuals. ${ }^{27}$ Daily sleepiness was significantly associated with low scores of physical, psychological and environmental quality of life..$^{28}$ An example of this is a study 1074 university students. Those diagnosed with chronic insomnia also reported poor quality of life. ${ }^{24}$

When students enroll in a nursing degree program, they become exposed to several stressful situations. These situations may make them vulnerable to changes in health status, including stress, depressive symptoms, sleep quality and reduced quality of life. On other hand, some students do not experience stress despite exposure to similar stress-inducing factors. These students may be at lower risk of negative health outcomes. ${ }^{29,30}$ The individuals' ability to adapt to stressful situations is named resilience. ${ }^{31,32}$ Resilience is characterized as a dynamic process that includes the interactions among the person, the social environment and the family. Resilience allows the individual to cope, 'win', and be strengthened when faced with adversity and stressful experiences. ${ }^{32,33}$ Thus, resilience has been described as an individual trait that promotes health by relieving stress, anxiety, anger and depression. In one study resilient individuals living in five North American states presented lower stress levels and depressive symptoms, as well as higher quality of life scores when compared to non-resilient ones..$^{29}$ An investigation with 2,069 medical students in three Chinese universities describes found that resilience has a moderating effect on students' health issues. ${ }^{30}$

In this sense, although several studies have been conducted there remain gaps in the scientific literature:

A. Longitudinal health analysis one year after starting the nursing degree program. In this study we will describe changes in students' health that may be linked to the nursing degree program.
B. Causal relationships among nursing students' health conditions (Stress, Depressive Symptoms, Sleep Quality, Quality of Life and Resilience) will be determined. This may allow us to predict factors that contribute to students' health changes.

C. Studies of resilience in college students are limited in Brazil, especially those conducted with nursing students. Once these relationships are understood, it will be possible to develop and apply interventions to promote resilience, decreasing the risks to students' health.

\section{Based on the gaps described above, we ask}

A. What are the possible changes in health status of nursing students one year after starting the nursing degree program?

B. What is the impact of Stress, Depressive Symptoms, Sleep Quality and Resilience on nursing student's quality of life one year after starting the nursing degree program?

\section{Aims}

A. Aim 1: to describe the health status of nursing students one year after starting the nursing degree program;

B. Aim 2: to analyze the impact of Stress, Depressive Symptoms, Sleep Quality and Resilience on nursing students' quality of life one year after starting the nursing degree program.

\section{Research hypothesis}

Significant relationships are predicted based on the literature and the theoretical framework. They were made according to each aim of this study, as follows:

\section{Assessment of changes in nursing students' health status}

Hypotheses: Changes in nursing students' health status will occur one year after starting the nursing degree program. At the end of one year, we expect to find increased levels of stress; poor sleep quality; increased occurrence of Depressive Symptoms; and poor sleep quality. Additionally, we expect that few students improve their resilient features through the experiences with academic stress factors.

\section{Assessment of phenomena behaviors}

Hypotheses (Figure 1): Students in a nursing degree program will be exposed to academic stressors that will increase their stress levels. ${ }^{2,3}$ This increase in stress will be associated with Depressive Symptoms, ${ }^{18}$ poor Sleep Quality ${ }^{14-17,22}$ and poor Quality of Life. ${ }^{19,34-37}$ Students with Depressive Symptoms ${ }^{34}$ and poor Sleep Quality ${ }^{24}$ are more likely to report lower quality of life.

Sleep Quality may affect the cognitive functions, increasing the risk of Depressive Symptoms. ${ }^{25-26}$

Depressive Symptoms contribute to decrease the sleep quality. ${ }^{21}$

Resilience may directly contribute to better Quality of Life. ${ }^{29}$

Resilience moderates the effect of stress ${ }^{29,30}$ on Sleep Quality and Depressive Symptoms. ${ }^{29,30}$ Thus, even under stress, students may present with good Quality of Life. 


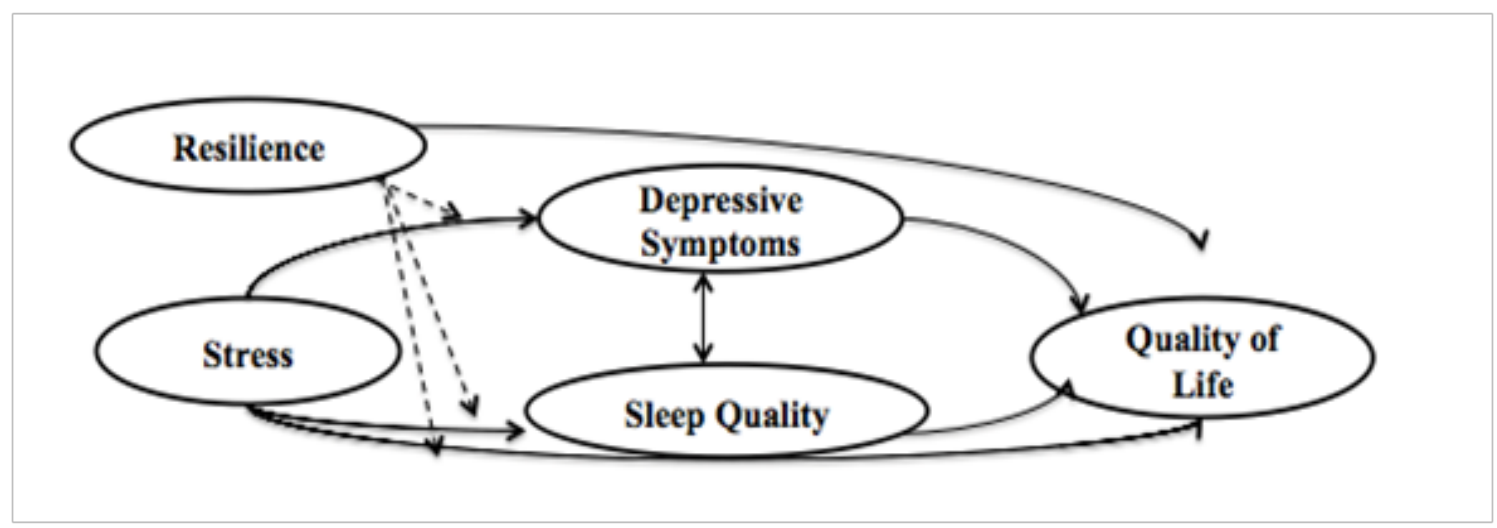

Figure I Hypothetic Model for health phenomena behaviors in Phase 3. São Paulo, 2015.

Source: Silva RM. Changes in nursing students' health one year after starting the nursing degree. Sao Paulo: EEUSP; 20 I5.

\section{Method}

\section{Study designs}

Initially, all instruments will be calibrated. This will ensure that they are adjusted and stable for the sample. This Phase will be done with confirmatory and exploratory factor analyses (Phase1- Calibration of measure instruments). Then, a prospective longitudinal study will be performed to describe the health status of nursing students one year after starting the nursing degree program (Phase 2- Assessment of changes in nursing students' health status). This design consists in following a sample of nursing students for one year. It allows measuring variables that will predict future outcomes. ${ }^{38}$ For the third Phase (Assessment of constructs behaviors), a methodological study through the structural equation modeling will be performed. This kind of analysis allows for identifying multiple dependency relations among constructs (latent variables), and, so, testing the hypothethical model of this research proposal. All Phases of these investigations will be conducted using quantitative approaches. ${ }^{39,40}$

\section{Place and population of study}

This research will be conducted at two public Brazilian University from Sao Paulo (state). All students enrolled in first semester of these schools and who voluntary accept to participate of this investigation under the signature of the Free and Informed Consent Term will be recruited. We expect about 160 students ( 80 from each university) will be enrolled in the study.

\section{Inclusion and exclusion criteria}

A. Students regularly enrolled in first semester of EEUSP and aged over 18 years will be included.

B. Students who will participate in data collection as research assistants will be excluded.

C. Students reproved in disciplines of the first semester will be excluded at the second time point.

\section{Study variables}

Aim 1: Assessment of changes in nursing students' health status
Predictor Variables- Nursing degree environment. Outcome Variables- Stress, Depressive Symptoms, Sleep Quality, Resilience and Quality of Life. Confounding Variables- Previous experience with those stressors as stressors prior to nursing program starting. It may contribute for a changed health status at the beginning of course. Also, previous experiences with stressors may strength the nursing students' coping skills, what implies lower risk of changes in health status after one year.

Aim 2: Assessment of the impact of stress, depressive symptoms, sleep quality and resilience on quality of life

a. Predictor Variables: Stress

b. Mediator variable: Depressive Symptoms and Sleep Quality

c. Moderator variable: Resilience

d. Outcome Variable: Quality of Life

\section{Data gathering and tools}

Data gathering will be conducted in three Phases, as follows: Phase1- Calibration of instruments; Phase 2- Assessment of changes in nursing students' health status; and Phase 3- Assessment of constructs behaviors. Data will be collected online in the Phase 1 and so online as in presence (During the classes at university) in the Phase 2. Also, nursing students who attend the research group as scientific scholarships will be invited to collaborate with the data collection and will not be eligible to participate as subjects.

\section{Phase1: Calibration of instruments}

The calibration of instruments will be done in February 2016. Students enrolled in second, third and fourth years will receive the research protocol (consent forms and instruments) by e-mail. The quality of response process might be affected for the high number of items that compose the protocol. Initially we will send instruments 1, 2 and 3; and, then, the remaining instruments. Students will have 10 days to return the instruments. We expect that students will take no more than 30 minutes to complete all instruments.

Initially, the list of second, third and fourth years nursing students and the disciplines that will be lectured at nursing schools will be got at undergraduate office. Then, the next steps will be followed: 
Step 1: Date and time will be scheduled by e-mail with the faculty responsible for one of the nursing disciplines in order to present the study aims and the data gathering flow.

Step 2: After instructor approval a date and time will be scheduled to meet with students.

A. Step 3: Research aims will be presented in classroom and the free and informed consent terms will be delivered to those who accept to participate.

B. Step 4: Instruments 1,2 and 3 will be sent by email to those students who agreed. They will have 10 days for returning the instruments to the researchers by email.

C. Step 5: Instruments 4, 5, and 6 will be sent by email to those students who complete instruments 1,2 and 3. Again, they will have 10 days to return the instruments to the researchers by e-mail.

The instruments that will be used in this investigation were previously validated. ${ }^{2,27,31,41-44}$ In Phase 1 we will evaluate their stability (Capability to produce similar results across time in identic samples) and validity (Capability to measure what is intended to), especially the construct one. ${ }^{38}$

\section{Phase 2: Assessment of changes in nursing students' health status}

This Phase will be conducted with all students enrolled in first year of nursing degree program from March to December 2016. The same research protocol will be applied at the 2 time-points as follows: at the start of classes (March 2016) and at the end of second semester (December 2016/ last week of classes). This protocol will include: demographic and academic form (Instrument 1); Instrument for stress evaluation in nursing students (AEEE) (Instrument 2), Center for Epidemiologic Studies Depression Scale (CES-D) (Instrument 3), Pittsburgh Sleep Quality Index (PSQI) (Instrument 4); ConnorDavidson Resilience Scale (Cd-Risc-10) (Instrument 5); Instrument for Quality of Life Assessment (WHOQOL-Brief) (Instrument 6). D collection will be conducted in four steps (Figure 2).

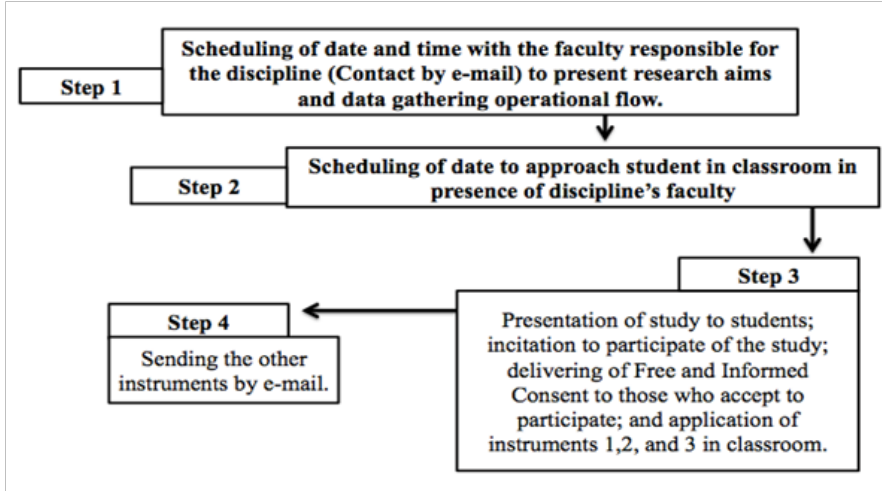

Figure 2 Data Gathering Flow. São Paulo, 2015.

Source: Adapted from Pires CGS. Risk factors to heart diseases among undergraduate students of first and last college years. Salvador:UFBA: 2013.

Initially, the list of first year nursing students and the disciplines that will be lectured at nursing schools will be got at undergraduate office. Then, the next steps will be followed:

Step 1- Date and time will be scheduled by e-mail with the faculty responsible for one of the nursing disciplines in order to present the study aims and the data gathering flow.
Step 2- After authorized by the faculty, a date and time will be scheduled to meet students.

A. Step 3-Research aims will be presented in classroom and the free and informed consent terms will be delivered to those who accept to participate. Also, student will get instruments 1,2 and 3 at this moment. We expect that this step takes about 30 minutes to be completed.

B. Step 4-Instruments 1,2 and 3 will be sent by email to those students who accepted to participate. They will have 10 days for returning the instruments to the researchers by e-mail.

C. Step 5-The other instruments will be sent by e-mail with a deadline of 10 days to be returned to the researcher. The time to response these instruments may change according the students' availability. However, we expect that students take no longer than 30 minutes to fill them.

The same data gathering flow will be done at the end of $2016^{45-51}$

\section{Phase 3: Assessment of constructs behaviors}

Phase 3 will be conducted from January to March 2017. We will apply the Structural Equation Modeling (SEM) to verify the relations among the constructs (latent variables), and to define/confirm the role of each one (predictors, mediators, moderators, outcome) according to the hypothetical models..$^{52,53}$ Thus, the impact of stress, depressive symptoms, sleep quality and resilience on quality of life will be described. Before proceeding to SEM, the relation between latent variables (stress, depressive symptoms, sleep quality and resilience and quality of life) and their observed variables (items and factors) will be examined through the Confirmatory Factor Analysis.

A simple Confirmatory Factor Analysis (CFA) aims to assess the measurement model, i.e., the relations among constructs and their observable variables. It is made by four steps, as follows: 1Development of individual constructs; 2- Development of overall measuring model; 3- Planning a study to gather empirical data; and 4- Assessment of the measuring model validity. SEM includes these four steps and two additional steps (Step 5- Specification of Structural Model; and Step 6- Assessment of structural model validity). These last two steps aim to assess the structural model, i.e., the relations among the constructs that compose the hypothetic model. ${ }^{53,54} \mathrm{We}$ have already satisfied steps $1,2,3$, and 5 , being that the two other steps will be satisfied when the empirical data will be gathered. In Figure 3 \& Figure 4, we respectively present the measurement model and the structural model hypothesized for this investigation.

\section{Data Analysis}

The Statistical Package for Social Sciences (SPSS, version 10.0) and their complement AMOS will be used for data analysis. The tools that compose the research protocol will be analyzed according to the analysis proposed by theirs authors. Qualitative variables will be summarized in absolute (n) and percent (\%) values. Quantitative variables will be presented in descriptive measures: minimum and maximum values, mean, standard deviation.

\section{Phase 1: Calibration of data gathering instruments}

The exploratory factor analysis (EFA) and, then, the Confirmatory Factor Analysis (CFA) will be proceeded. In the EFA, the KaiserMeier-Oklin (KMO) and the Bartlett's Test of Sphericity as sample adequacy measures, being considered $\mathrm{KMO}>0.5$ and $\mathrm{p}$-value $<0.05$ as 
adequate values to proceed the factorial analysis of each instrument. ${ }^{52}$ The definition of the number of factors will follow the assessment of total explained variance (At least $60 \%$ ) based on eigenvalues $>1,0$ and screeplot. ${ }^{52}$ The method of Unweighted Least Squares with oblique rotation, oblimin type, will be run to data exploration explore the set of data. Alpha (Corrected Item-Total Correlation; and total Alpha) will be applied to explore the instruments' internal consistency. All of these indicators allow identifying collinearity (values above the cutpoints) and low discriminatory power (values below the cut-points). In case of colinearity, the Variance Inflation Factor (VIF) will be run to confirm this situation, what occurs when VIF $>10.0$ (Table 1)..$^{52}$
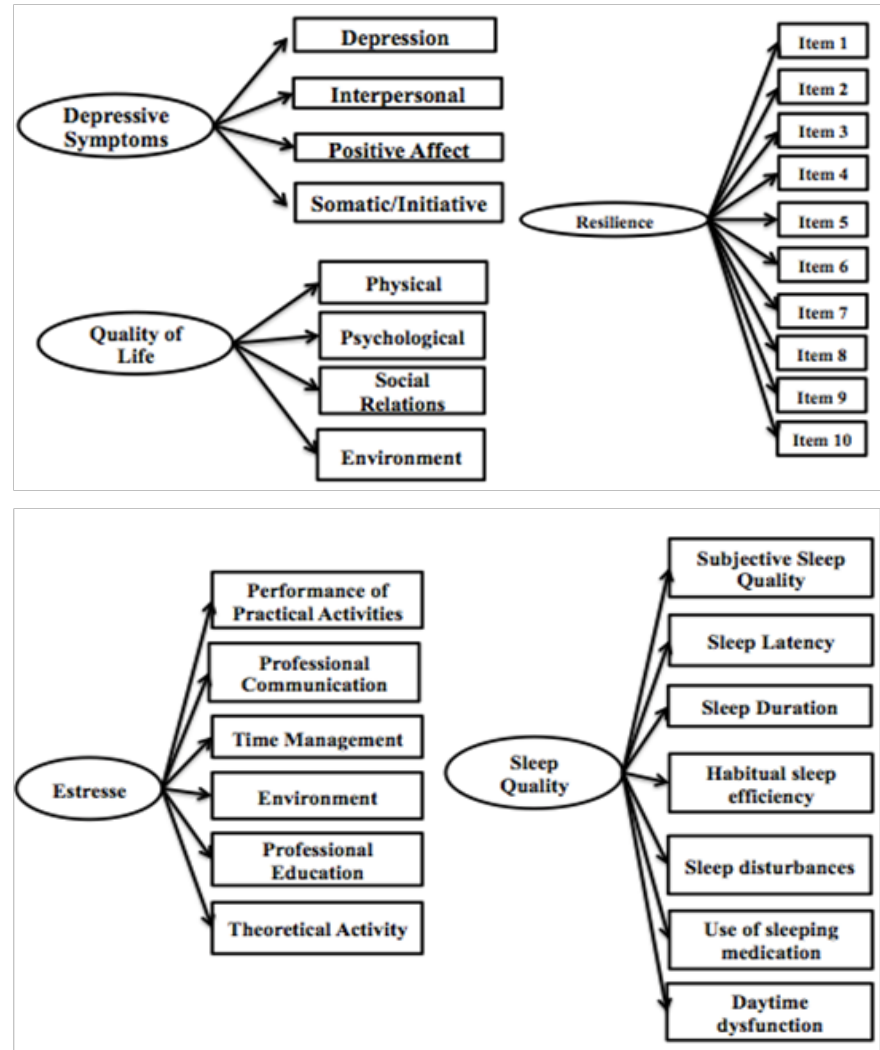

Figure 3 Measurement Model with the indicator for all latent variables included in the Phase 3 model. São Paulo, 2015

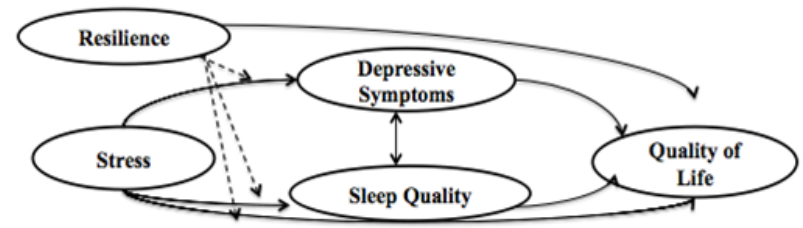

Figure 4 Hypothetic Model for health constructs behaviors in Phase 3. São Paulo, 2015.

Source: Silva RM. Changes in nursing students' health one year after starting the nursing degree. Sao Paulo: EEUSP; 2015.

The Confirmatory Factor Analysis will be applied to confirm the internal structure underlying the set of variables found in EFA. As adjustment indexes, the minimum required is at least one Incremental Index, one Absolut Index, beyond the Chi-square $\left(\mathrm{X}^{2}\right)$ and Degrees of Freedom (DF), and one Index of Poor Quality Fitness. ${ }^{52}$ The
Absolut measures will be: $X^{2}$ (Adjustment $=>0,05$ ), Standardized $X^{2}$ (Adjustment $=<3,0$ ) that is based on the DF, and Goodness Fitness Index (GFI)(Adjustment $=>0,95)$. As Incremental Indexes, we selected the Comparative Fitness Index (CFI)(Adjustment $>0,92)$ and the Tucker Lewis Index (TLI)(Adjustment $=>0,92) .{ }^{52}$ Two indexes of poor quality fitness will be applied, as follows: Root Mean Square Error of Approximation (RMSEA) (Adjustment $=r<0,08$ considering a CFI $>0,92$ ) and Standardized Root Mean Square Residual (SRMR) (Adjustment $=r<0,09$ considering a $\mathrm{CFI}>0,92$ ). ${ }^{52}$ In addition to these indexes, Factor Load (Adjustment $=0,4-0,6$ ) and Pearson Correlation $(0,5-0,7)$ will allow to assess the impact of each observable variable on the latent variables. ${ }^{52}$

Table I Cut-points to evaluate the maintenance of items into the instruments. Sao Paulo 2015 Hair. $^{52}$

\begin{tabular}{|c|c|c|c|}
\hline Indicator & $\begin{array}{l}\text { Adequate } \\
\text { values }\end{array}$ & Collinearity & $\begin{array}{l}\text { Low } \\
\text { discriminatory } \\
\text { power }\end{array}$ \\
\hline Pearson Correlation & $0.5-0.7$ & $>0.90$ & $<0.50$ \\
\hline Communality & $0.4-0.6$ & $>0.80$ & $<0.4$ \\
\hline Factor Load & $0.4-0.7$ & $>0.85$ & $<0.4$ \\
\hline $\begin{array}{l}\text { Variance Inflation } \\
\text { Factor (VIF) }\end{array}$ & $0-10$ & $>10$ & - \\
\hline Cronbach's Alpha & $0.7-0.9$ & $>0.90$ & $<0.6$ \\
\hline $\begin{array}{l}\text { Corrected Item- } \\
\text { Total Correlation }\end{array}$ & $0.3-0.8$ & $>0.80$ & $<0.30$ \\
\hline
\end{tabular}

\section{Phase 2: Assessment of changes in nursing students' health}

ANOVA for repeated measures will be used to compare the means of each construct across time. Also, longitudinal regression will be performed to verify the presence of factors beyond the academic environment that may affect the observed variations. P values $<0.05$ will be considered statistically significant. Instrument reliability will be determined by Cronbach's Alpha.

\section{Phase 3: Assessment of constructs behaviors}

As described above, after data gathering, the validity of the measuring and structural models will be examined respectively through the Confirmatory Factor Analysis and Structural Equation Modeling. Data from the first gathering will be used for all predictors, mediator e moderator variables included into the model, and data from both gathering will be used to quality of life variation analysis. Thus, the impact of those phenomena experienced for students in beginning of the nursing degree on the quality of life variation (Subtraction of final QoL scores from initial Qol scores) will be obtained. Adjustment indexes that we will apply here are the same used in the Confirmatory Factor Analyses of the Calibration Instruments Phase (See item 4.5.1).

\section{Ethical aspects}

The Research Ethical Committee of the University of Sao Paulo has approved this project. Once this investigation will be done with human beings, the confidentially term and the Free and Informed Consent Term (FICT) were submitted to the Ethical Committee for evaluation and they are already approved for the committee. The FICT will be delivered with the protocol to all individuals who agreed to participate of the study. Concomitantly, the project was sent to the Research Office at the Schools of Nursing where it was evaluated regarding viability and merit, being approved in December 2015. 
The development of this research, from the project improvement to the spreading results Phases, will be conducted in partnership with the Prof. PhD. Margaret Heitkemper. She is a reference in clinical and emotional symptoms association field and works in the Biobehavioral Nursing and Health Systems Department at School of Nursing of the University of Washington.

\section{Acknowledgements}

None.

\section{Conflict of interest}

Authors declare there is no conflict of interest in publishing the article.

\section{References}

1. Costa ALS. Estresse em estudantes de enfermagem: construção dos fatores determinantes. REME rev min enferm. 2007;11(4):414-9.

2. Costa ALS, Polak C. Construção e validação de instrumento para avaliação de estresse em estudantes de enfermagem (AEEE). Rev ESC Enferm USP. 2009;43:1017-26.

3. Bayram N, Bilgel N. The prevalence and socio-demographic correlations of depression, anxiety and stress among a group of university students. Soc Psychiatry Psychiatr Epidemiol. 2008;43(8):667-72.

4. Killam LA1, Mossey S, Montgomery P, et al. First year nursing students' viewpoints about compromised clinical safety. Nurse Educ Today. 2013;33(5):475-80

5. Montgomery P, Mossey S, Killam L. Views of second year nursing students on impediments to safety in the clinical setting: Q-methodology. J Nurs Educ Pract. 2013;3(8):1-12.

6. Häfner A, Stock A. Time management training and perceived control of time at work. J Psychol. 2010;144(5):429-47.

7. Häfner A, Stock A, Pinneker L, Ströhle S. Stress prevention through a time management training intervention: an experimental study. Educ Psychol. 2014;34(13):403-16.

8. Bublitz S, Freitas EO, Kirchhof RS, et al. Estressores entre acadêmicos de enfermagem e uma universidade pública. Rev enferm UERJ. 2012;20(N esp 2):739-45.

9. Labrague LJ. Stress, Stressors, and Stress Responses of Student Nurses in a Government Nursing School. Health Sci J. 2013; 7(4): 424-35.

10. Wong Wai Yi W. The Relationship between Time Management, Perceived Stress, Sleep Quality and Academic Performance among University Students [monografia]. Hong Kong: Hong Kong Baptist University; 2008.

11. Lazarus RS, Folkman S. Stress, appraisal, and coping. New York: Springer; 1984.

12. Basso Musso L, Vargas BA, Torres MB, et al. Fatores derivados dos laboratórios intra-hospitalares que provocam estresse nos estudantes de enfermagem. Rev latinoam enferm. 2008;16(5):805-11.

13. Silva RM, Goulart CT, Lopes LFD, et al. Avaliação de estresse em estudantes de enfermagem - proposta de padronização da análise. In: Rossi AM, Meurs JA, Perrewé PL, editors. Stress e qualidade de vida no trabalho: melhorando a saúde e bem-estar dos funcionários Porto Alegre: Atlas; 2013. p. 55-67.

14. Garlow SJ, Rosenberg J, Moore JD, et al. Depression, desperation, and suicidal ideation in college students: results from the American Foundation for Suicide Prevention College Screening Project at Emory
University. Depress Anxiety. 2008;25(6):482-8.

15. Craggs S. One-third of McMaster students battle depression: survey Califórnia: CBC News; 2012.

16. Yusoff MS, Abdul Rahim AF, Baba AA, et al. Prevalence and associated factors of stress, anxiety and depression among prospective medical students. Asian J Psychiatr. 2013;6(2):128-33.

17. Moreira DP, Furegato ARF. Estresse e depressão entre alunos do último período de dois cursos de enfermagem. Rev latinoam enferm. 2013;21:155-62.

18. Lund HG, Reider BD, Whiting AB, et al. Sleep patterns and predictors of disturbed sleep in a large population of college students. J Adolesc Health. 2010;46(2):124-32.

19. Bhandari P. Stress and health related quality of life of Nepalese students studying in South Korea: a cross sectional study. Health Qual Life Outcomes. 2012;10:26.

20. Gorenstein C, Andrade L. Inventário de Depressão de Beck: propriedades psicométricas da versão em português. Rev psiquiatr clín (São Paulo). 1998;25(5):245-50.

21. Guo L, Deng J, He Y, et al. Prevalence and correlates of sleep disturbance and depressive symptoms among Chinese adolescents: a cross-sectional survey study. BMJ Open. 2014;4(7):1-9.

22. Sawatzky RG, Ratner PA, Richardson CG, et al. Stress and depression in students: the mediating role of stress management self-efficacy. Nurs Res. 2012;61(1):13-21.

23. Hicks RA, Fernandez C, Pellegrini RJ. Striking changes in the sleep satisfaction of university students over the last two decades. Percept Mot Skills. 2001;93(3):660.

24. Taylor DJ, Bramoweth AD, Grieser EA, et al. Epidemiology of insomnia in college students: relationship with mental health, quality of life, and substance use difficulties. Behav Ther. 2013;44(3):339-48.

25. Vanderlind WM, Beevers CG, Sherman SM, et al. Sleep and sadness: exploring the relation among sleep, cognitive control, and depressive symptoms in young adults. Sleep Med. 2014;15(1):144-9.

26. Coelho AT, Lorenzini LM, Suda EY, et al. Sleep Quality, Depression and Anxiety in College Students of Last Semesters in Health Area's Courses Neurobiologia. 2010;73(1):35-9.

27. Ferrans CE, Powers MJ. Psychometric assessment of the Quality of Life Index. Res Nurs Health. 1992;15:29-38.

28. Fiedler PT. Avaliação da qualidade de vida do estudante de medicina e da influência exercida pela formação acadêmica. São Paulo: Faculdade de Medicina, Universidade de São Paulo; 2008.

29. Dyrbye LN, Power DV, Massie FS, et al. Factors associated with resilience to and recovery from burnout: a prospective, multi-institutional study of US medical students. Med Educ. 2010;44(10):1016-26.

30. Peng L1, Zhang J, Li M, et al. Negative life events and mental health of Chinese medical students: the effect of resilience, personality and social support. Psychiatry Res. 2012;196(1):138-41.

31. Lopes VR, Martins MCF. Validação Fatorial da Escala de Resiliência de Connor-Davidson (Cd-Risc-10) para Brasileiros. Rev psicol organ trab. 2011;11(2):36-50.

32. Luthar SS, Cicchetti D, Becker B. The Construct of Resilience: a critical evaluation and guidelines for future work. Child Development. 2000;71:543-562.

33. Grotberg EH. Introdução: novas tendências em resiliência. In: A. Melillo, ENS Ojeda, editors. Resiliência: descobrindo as próprias fortalezas (pp.15-22). Porto Alegre: Artmed; 2005. 
34. Souza IM, Paro HB, Morales RR, et al. Health-related quality of life and depressive symptoms in undergraduate nursing students. Rev latinoam enferm. 2012;20(4):736-43.

35. Prieto-Miranda SE, Rodríguez-Gallardo GB, Jiménez-Bernardino CA et al. Burnout and quality of life in medical residents. Rev Med Inst Mex Seguro Soc. 2013;51(5):574-9.

36. Amaducci CM, Mota DDFC, Pimenta CAM. Fadiga entre estudantes de graduação em enfermagem. Rev esc enferm USP. 2010;44(4):1052-8.

37. Mathews D. Assessing Sleep Quality in Young Adult College Students, Aged 18 - 24 in Relation to Quality of Life and Anthropometrics. Bangor: Graduate Program in Food Science and Human Nutrition, The University of Maine; 2010.

38. Hulley SB, Cummings SR, Browner WS, et al. Delineando a pesquisa clínica. 3rd ed. Porto Alegre: Artmed; 2008.

39. Sousa VD, Driessnack M, Mendes IAC. An overview of research designs relevant to nursing. part 1: quantitative research designs. Rev latinoam enferm. 2007;15(3):502-7.

40. Silveira DX, Jorge MR. Escala de rastreamento populacional para depressão CES-D em populações clínicas e não clínicas de adolescentes e adultos jovens. In: Gorestain C, Andrade LHSG, Zuarde AW, editors. Escalas de avaliação clínica em psiquiatria e farmacologia. São Paulo: Lemos Editorial; 2000.

41. Filho NK, Teixeira MAP. A estrutura fatorial da Escala CES-D em estudantes universitários brasileiros. Aval psicol. 2011;10(1):91-7.

42. Radloff LS. The CES-D Scale: a self-report depression scale for research in the general population. Appl psychol meas. 1977;1(3):385-401.

43. Buysse DJ, Reynolds CF, Monk TH, et al. The Pittsburgh Sleep Quality Index: a new instrument for psychiatric practice and research. Psychiatr Res. 1989;28:193-213.

44. Bertolazi AN. Tradução, adaptação cultural e validação de dois instrumentos de avaliação do sono: escala de sonolência de Epworth e índice de qualidade de sono de Pittsburgh. Porto Alegre: Escola de Medicina, Universidade Federal do Rio Grande do Sul; 2008.
45. Benavente SBT, Silva RM, Higashi AB, et al. Influência de fatores de estresse e características sociodemográficas na qualidade do sono de estudantes de enfermagem. Rev Esc Enferm USP. 2014;48(3):514-20.

46. Cardoso HC, Bueno FCC, Mata JC, et al. Avaliação da qualidade do sono em estudantes de Medicina. Rev bras educ Med. 2009;33(3):349-55.

47. Cavagione LC. Influência do Plantão de 24 horas sobre a pressão arterial e o perfil de risco cardiovascular em profissionais da área da saúde que atuam em serviços de atendimento pré-hospitalar. São Paulo: Escola de Enfermagem, Universidade de São Paulo; 2010

48. Campbell-Sills L, Stein MB. Psychometric Analysis and Refinement of the Connor-Davidson Resilience Scale (CD--RISC): Validation of a 10Item Measure of Resilience. J Trauma Stress. 2007;20:1019-1028.

49. Connor KM, Davidson JRT. Development of a new resilience scale: The Connor- Davidson Resilience Scale (CD-RISC). Depress Anxiety. $2003 ; 18: 76-82$.

50. Brasil. Ministério da Saúde. Secretaria de Políticas de Saúde. Como está sua alimentação? Brasília; 2007.

51. The WHOQOL Group. Development of the World Health Organization WHOQOL-BREF quality of life assessment. Psychol Med.1998;28(3):551-8.

52. Hair Jr JF, Anderson RE, Tatham RL, et al. Análise multivariada de dados. 5th ed. Porto Alegre: Bookman; 2005.

53. Pilati R, Laros JA. Modelos de Equações Estruturais em Psicologia: Conceitos e Aplicações. Psicol teor pesqui. 2007;23(2): 205-16.

54. Schumacker RE, Lomax RG. A Beginner's Guide to Structural Equation. 3rd ed. Ohio(OH): Routledge; 2010. 